\title{
Optimising an integrated crop-livestock farm using risk programming
}

\author{
SE Visagie* $\mathrm{HC}$ de $\mathrm{Kock}^{\dagger}$ Ghebretsadik $\mathrm{AH}^{\dagger}$ \\ Received: 23 July 2004; Revised: 15 October 2004; Accepted: 18 October 2004
}

\begin{abstract}
Numerous studies have analysed farm planning decisions focusing on producer risk preferences. Few studies have focussed on the farm planning decisions in an integrated croplivestock farm context. Income variability and means of managing risk continues to receive much attention in farm planning research. Different risk programming models have attempted to focus on minimising the income variability of farm activities. This study attempts to identify the optimal mix of crops and the number of animals the farm needs to keep in the presence of crop production risk for a range of risk levels. A mixed integer linear programming model was developed to model the decision environment faced by an integrated crop-livestock farmer. The deviation of income from the expected value was used as a measure of risk. A case study is presented with representative data from a farm in the Swartland area. An investigation of the results of the model under different constraints shows that, in general, strategies that depend on crop rotation principles are preferred to strategies that follow mono-crop production practices.
\end{abstract}

Key words: Farm planning, risk, return, integer programming

\section{Introduction}

Agricultural activity occurs in an environment that is always changing. In every growing season producers must pay attention to numerous factors that influence their management decisions. Some factors are within the control of the farmers; however, many are not. The weather, market conditions (including input and output prices), new technology, government policy and information represent some of the factors that have an impact on production decisions. The sustainability and profitability of a farm is dependent on the management of these broad categories of externalities. The farmer must deal with such factors on a continual basis [31]. The introduction of crop rotation into the farming activities increases the sustainability and profitability of agricultural production by decreasing the effect of weeds, pests and disease in the production process, but the unpredictability of

\footnotetext{
* Corresponding author: Department of Logistics, University of Stellenbosch, Private bag X1, Matieland, 7602, Stellenbosch, South Africa, email: svisagie@sun.ac.za

${ }^{\dagger}$ Department of Logistics, University of Stellenbosch, Private bag X1, Matieland, 7602, Stellenbosch, South Africa
} 
the weather and the markets from year to year present the farmers with serious challenges. Therefore agricultural production is becoming more risky. In dealing with this problem, the farmer needs to develop a management strategy that allows him to minimise these effects in the production process.

The aim of this paper is to point out how the introduction of crop rotation alternatives influence the decision planning of an integrated crop-livestock farming operation in the presence of risk. To investigate this issue a mathematical model for farm planning is developed, incorporating the different activities of the farm under consideration. The problem is therefore to determine farm planning strategies that optimise the profit earned from the activities, which include the selection of crop rotation strategies in a rotary crop system, the number of animals and their required feed, and the amount of crop to sell to the market for a range of risk levels.

\section{Risk and uncertainty in agriculture}

Agricultural production in South Africa is risky. Farmers face risks that emanate from a combination of price, yield and resources, that make their income unstable from year to year [12]. Under conditions of price and output uncertainty a farmer has to make decisions based on imperfect information. Risk and uncertainty constitute a strong behavioral force in the decision-making process because of their strong influence on the efficiency of resource-use. At present there is much debate on research issues related to risk and uncertainty in agricultural production and their influence on the expected outcome or yield from agricultural products $[1,10,12]$. The omission of risk in decision models on farm level may lead to results that bear little, if any, similarity to farmers' actual situation [1]. Agricultural decision models that do not include risk considerations may overestimate outputs of risky activities and fail to recognise the importance of diversification in agricultural production systems [38]. Ignoring risk may also lead to over-valuation of some inputs. This can, for instance, lead to incorrect prediction of technology choices [15]. Empirical applications of behavioural models and theoretical considerations indicate the importance of incorporating risk into the analysis of agricultural decision-making on farm level.

Static economic analysis is based on simplified assumptions of certainty about the production environment and considers only an objective of profit maximisation [1]. Linear programming models for farm activities are based on this premise. The solutions generated by such modelling tools would not satisfy risk-averse farmers [14]. Introduction of risk into a mathematical model extends such concepts to include the decision-maker's perception of risk and his/her attitude toward risk.

Various risk-modelling techniques have been developed during the past 40 years to address risk in agricultural decision-making. A number of risk concept models and their analytical implementation may be found in the literature $[1,10]$. Generally, three approaches to risk and uncertainty programming have been used [3]: (1) those requiring no probability information (games against nature), (2) safety-first approaches, and (3) expected utility maximisation [40]. 


\subsection{Game theoretic approach}

Game theoretic decision models constitute one of the main conventional approaches to agricultural decision-making under uncertainty [23, 24, 33]. In this approach the decisionmaker's problem is described as a two-person zero-sum game. All the risk and uncertainty components facing the decision-maker can be summarised as a composite contribution by the player called nature [12]. In the game theory modelling framework for agricultural production a clear definition of "nature" and the decision-maker is important. The key features of games against nature are: (1) the existence of a decision-maker (farmer) who is considered as the only rational player of the game, (2) the decision-maker (farmer) has a set of $n$ possible strategies or actions to follow, and (3) the existence of a set of $h$ different possible states of nature representing the uncertainties within which the decision-maker operates. Such games are represented by an $n \times h$ matrix whose $(i, \tau)^{t h}$ element represents the outcome of the game when the decision-maker chooses the $i^{t h}$ strategy to face the $\tau^{t h}$ state of nature [29].

The aim of a game theoretic model is to find a pure or mixed strategy that optimises the objective function (wishes and aspirations) of a decision-maker under different constraints and limitations of resources. This is based on the idea that game theory assumes all important states can be enumerated, but avoids an explicit assumption about the probabilities of future occurrence [13]. This approach was introduced to agricultural decision-making by McInnerney $(1967,1969)$. A set of available strategies was defined as those that corresponded to a feasible set of solutions to an ordinary linear programming problem. Additionally, he defined the elements of the payoff matrix of the game as the observed gross margins over past years.

A number of criteria have been used to represent the aspirations of a decision-maker in the game theoretic model $[12,29]$. Some of the well-known criteria that have been applied in agricultural decision-making under uncertainty are (1) the maxmin (Wald Criterion), (2) the minimax regret (Savage Criterion), and (3) the benefit criterion. Some of these models assume that decision-makers have no objective information or subjective feeling about the probabilities associated with alternate outcomes. They totally ignore whatever information the decision-maker may have. The main criticism of such models stems from this lack. Such models may also be criticised on the grounds, that the decision criteria employed are incompatible with the axioms of rational choice underlying decision analysis [1]. Other models of games against nature assume that nature acts as a conscious opponent of a decision-maker, that is, it strives to limit the expected payoff to the minimum. Such a view may suit the pessimistic or cautious decision-maker, but may not be attractive to an optimistic decision-maker. The assumption that nature is malicious is certainly not accurate. Nature neither consciously favours nor hinders a decision-maker. As a result the application of such models is fairly limited in the modelling of farm planning [17].

\subsection{The safety-first approach}

The safety-first approach to risk programming is commonly used in risk analysis as a form of lexicographic utility [28]. This approach to risk management is applicable if a decision problem's primary aim is to satisfy a preference for safety (such as minimising 
the probability of bankruptcy) when making decisions about agricultural activities. This means that only when the safety goal has been met at a threshold level, can the other goals be addressed. Thus, the highest priority goal serves as a constraint on goals that have lower priorities [4]. Safety-first rules usually describe three approaches: (1) a decisionmaker maximises expected return subject to the constraint that the probability of income below some specific level is small enough (Telser's rule); (2) the decision-maker maximises income at the lower confidence limit, subject to the constraint that the probability of income being lower than the lower limit does not exceed a specified value (Kataoka's rule); or (3) the decision-maker simply minimises the probability that income will be lower than some specified level (Roy's rule) [4, 28].

Safety-first mathematical programming methods are particularly applicable where survival of the business is of paramount concern. The term "safety-first" has considerable intuitive attraction, because it implies that a decision-maker first satisfies a preference for safety in organising a firm's activities and then maximises profit within this safety scheme. However, in most business risk management situations the use of safety-first methods is somehow arbitrary, as no single goal can be clearly dominant amongst a set of alternative goals. Moreover, it should be noted that some theoretical generalisation of "safety-first" decision rules leads to a lexicographic utility preference which is inconsistent with the expected utility approach. There is no utility function that is able to represent lexicographic utility preference because of the lack of continuity [4].

\subsection{The 'E-V' approach (quadratic programming)}

A classic problem in uncertainty and risk analysis involves determining an optimal allocation of resources across a range of risky alternatives. It is well understood that risk-averse decision-makers seek to reduce the effect of uncertainty and risk in the expected returns. This modelling approach is one of the modelling tools based on expected utility maximisation theory $[1,12]$. The first attempt to take explicit account of risk in mathematical programming formulations of a farming activity planning problem was by quadratic risk programming. Markowitz (1952) provides a theoretical foundation for portfolio selection employing the first two moments of return distributions. Given various combinations of mean $(E)$ and variance $(V)$ of portfolios, there exists a set of efficient E-V pairs. Markowitz $(1952,1959)$ described the portfolio quadratic programming framework and specified the objective to minimise portfolio variance for alternative levels of expected return. To obtain an efficient $\mathrm{E}-\mathrm{V}$ set, it is necessary to minimise the variance $(V)$ for each possible level of expected income $(E)$, while retaining feasibility with respect to available resource constraints and other activities. The relevant programming model to achieve such a possible level of expected income is described by the following mathematical model $[1,12]$ :

$$
\begin{aligned}
& \text { Minimise } V=\sum_{i=1}^{n} \sum_{j=1}^{n} X_{i} \sigma_{i j} X_{j} \\
& \text { subject to } \\
& \sum_{i=1}^{n} \bar{C}_{i} X_{i} \quad \geq \lambda
\end{aligned}
$$




$$
\begin{aligned}
\sum_{i=1}^{n} a_{i j} X_{i} & \left\{\begin{array}{l}
= \\
\leq \\
\geq
\end{array}\right\} \quad b_{j} \quad j=1,2, \ldots, m \\
X_{i} & \geq 0 \quad \forall i,
\end{aligned}
$$

where $\bar{C}_{i}$ denotes the expected gross margin of each risky investment of activity $i ; \mathrm{X}_{i}$ represents the level of the $i^{\text {th }}$ farming activity; $\lambda$ is a scalar denoting minimum expected profit; $\sigma_{i j}$ is the covariance returns on activities $i$ and $j ; a_{i j}$ is the $(i, j)^{t h}$ coefficient in the set of $m$ linear constraints; and $b_{j}$ is the $j^{\text {th }}$ the right hand side in the set of linear constraints.

An alternative approach is to maximise a quadratic function of activity levels subject to linear constraints $[1,8]$. That is,

$$
\begin{aligned}
& \text { Maximise } z=\sum_{i=1}^{n} \bar{C}_{i} X-\lambda \sum_{i=1}^{n} \sum_{j=1}^{n} X_{i} \sigma_{i j} X_{j} \\
& \text { subject to } \\
& \sum_{i=1}^{n} \bar{C}_{i} X_{i} \quad \geq \quad \lambda \\
& \sum_{i=1}^{n} a_{i j} X_{i} \quad\left\{\begin{array}{c}
= \\
\leq \\
\geq
\end{array}\right\} \quad b_{j}, j=1,2, \ldots, m \\
& X_{i} \geq 0 \quad \forall i .
\end{aligned}
$$

In this model $\lambda$ is a lower bound on the expected gross margin, but it can also be considered as a parameter of risk. The reason for this is as follows. The objective function can be rewritten as $E-\lambda S$, but $E \geq \lambda$, which implies that $E=\lambda+W(X)$. Thus the objective function becomes $\lambda(1-S)+W(X)$. In this form $\lambda$ becomes a weight for $(1-S)$. It is clear that the optimisation will tend to render $W(X)$ as large as possible, while $S$ should be as small as possible. The value of $\lambda$ is thus an indication of how important $(1-V)$ (the risk) is.

The model in (1) is solved iteratively through parametric variations in $\lambda$ to define the riskefficient (minimum variance) solutions [12]. This is to say that one has to trace out the $\mathrm{E}-\mathrm{V}$ frontier and the quadratic programming problem must be solved parametrically as the risk aversion coefficient $\lambda$ varies from 0 to $\infty$. The $\mathrm{E}-\mathrm{V}$ frontier is die set of all optimal solution pairs of $\mathrm{E}-\mathrm{V}$ values. If the decision-maker is assumed to be risk neutral $(\lambda=0)$, the problem collapses to income maximisation, which may be solved with ordinary linear programming algorithms.

The use of the E-V risk modelling approach has disadvantages. Some of the limitations are briefly mentioned below.

1. The necessity of using a quadratic programming algorithm was considered a severe disadvantage in studies conducted in the 1970s and 1980s [12]. Due to the rapid growth of the computational capability of different solvers, however, this is no longer considered a problem, though the computational complexity is high compared to linear programming solution algorithms. 
2. Estimation of the variance-covariance matrix presents numerous methodological pitfalls. Preferably, variance-covariance should be based on the subjective evaluation of the decision-maker [2]. Most of the studies undertaken have taken objective measures of variability based on historical data. In such modelling activities key decisions include identifying relevant sources of risk, collecting the appropriate data as in the case of crop yields or prices, selecting the appropriate length of the historical series, etc. There is also a need to distinguish between known patterns of variation (trends, cycles, seasonal) and a random variation. The assumption that returns are normally distributed about the mean is another drawback of the approach, especially in observations which have skewed distribution [14].

3. Specifying the risk aversion coefficient is arbitrary, yet it is absolutely critical in determining a risk-efficient farm plan. There is no clear-cut measure of the risk aversion coefficient. One might derive the entire efficient frontier and present the set of farm plans to the decision-maker.

4. Variance as a measure of risk equally penalises both the upside and downside risk. However, from an agricultural producer's viewpoint, the downside variation is the important aspect of risk that the farmer needs to minimise [14].

\subsection{MOTAD}

A linear programming alternative to the E-V approach, that has been used widely in agricultural decision-making practice, was developed by Hazell (1971). He reduced the minimisation of variance to minimisation of mean absolute deviations (MAD). The technique is called MOTAD. The acronym MOTAD stands for minimisation of total absolute deviations. One concern associated with the $\mathrm{E}-\mathrm{V}$ formulation is that it results in a quadratic objective function as mentioned above. As a response to this problem MOTAD was developed, which linearly approximates E-V results, based on total absolute deviations. An additional concern that has been raised is that the assumption of a quadratic utility function is rather restrictive. If this assumption is imposed, it implies that absolute risk aversion increases with the level of payoff [10].

This approach closely parallels the quadratic programming (E-V) approach. It can be shown that this measure of risk may be incorporated into an enlarged linear programming model of a farm planning problem in such a way that mean absolute deviations can be minimised parametrically for a given level of expected profit value over the relevant range [14]. This approach is more relevant when mean absolute deviation of a farm income is estimated using a time series (or a cross-section thereof) of sample data. One version of the MOTAD risk programming model is described as follows $[1,10]$ :

$$
\text { Minimise } w \quad=\quad \sum_{\tau=1}^{s}\left(L_{\tau}^{+}+L_{\tau}^{-}\right)
$$

subject to

$$
\sum_{i=1}^{N}\left(C_{\tau i}-C_{i}\right) X_{i}-L_{\tau}^{+}+L_{\tau}^{-} \quad=\quad 0 \quad \tau=1,2, . . h
$$




$$
\begin{array}{cccc}
\sum_{i=1}^{N} C_{i} X_{i} & = & \lambda \\
\sum_{i=1}^{N} a_{i j} X_{i} & \left\{\begin{array}{l}
= \\
\leq \\
\geq
\end{array}\right\} & b_{j} & \forall j \\
X_{i}, L_{\tau}^{+}, L_{\tau}^{-} & \geq & 0 .
\end{array}
$$

Here $L_{\tau}^{+}, L_{\tau}^{-}$are positive and negative deviations, $\tau$ is an index that refers to the states of nature and $C_{i \tau}$ is the profit earned from farming strategy $i$ when the state of nature is $\tau$. The value of $C_{i}$ is the average profit form farming strategy $i$ over all the possible states of nature. The objective here is to minimise the sum of the deviations from the average profit. The first set of constraints set the deviation at the correct value, while the second set of constraints limits the size of all the possible activities on the farm.

Alternatively, the expected farm profit may be maximised with parametric constraints on the negative and positive deviations. That is, one could

$$
\operatorname{Maximise} E(Z)=\sum_{i=1}^{N} C_{i} X_{i}-\lambda\left(\sum_{\tau=1}^{s} L_{\tau}^{+}+L_{\tau}^{-}\right)
$$

subject to

$$
\begin{aligned}
\sum_{i=1}^{N}\left(C_{\tau i}-C_{i}\right) X_{i}-L_{\tau}^{+}+L_{\tau}^{-} & =0, \quad \tau=1,2, \ldots, h \\
\sum_{i=1}^{N} a_{i j} X_{i}\left\{\begin{array}{c}
= \\
\leq \\
\geq
\end{array}\right\} & b_{j} \quad \forall j \\
X_{i}, L_{\tau}^{+}, L_{\tau}^{-} & \geq 0,
\end{aligned}
$$

with $\lambda$ a parameter. The advantage of this model is that, unlike the quadratic programming model, the MOTAD approach does not require a variance-covariance matrix. However, MOTAD does consider the covariance relationship among activities. Deviations from the mean of the series for each activity are summed across all activities. Positive deviations in one activity may cancel out negative deviations in another activity, thus accounting for the correlation between activities. This is one of the advantages of the MOTAD approach in risk programming [12].

\subsection{Target-MOTAD}

Target-MOTAD is another risk programming model related to MOTAD. This risk-programming model was developed by Tauer as an extension of the MOTAD risk programming model. The Target-MOTAD model offers the additional advantage that the solution sets derived are contained in the set of plans that are second-degree stochastic efficient (SSD) $[32,22]$.

In this programming model risk is measured as the expected sum of the negative deviations of a solution from the target income level. Risk is parametrically varied so that a 
risk-return frontier is traced out. The development of Target-MOTAD as a risk programming model was the result of the shortcomings in the E-V and MOTAD risk programming models. If the returns of the farm activities are normally distributed, the solutions generated using the E-V approach are SSD efficient and are consistent with the expected utility theory. However, if the normality assumption is not satisfied, using the E-V model the analyst must determine whether or assume that the decision-maker has a quadratic utility function. In this case the results derived from the E-V method are not necessarily efficient [32].

The basic advantage of the MOTAD and Target-MOTAD risk programming models is that solutions can be generated by linear programming algorithms. Despite this important advantage of the MOTAD model, the results obtained in applying the MOTAD model are not necessarily SSD [32]. The Target-MOTAD risk programming model has two important advantages. First, the Target-MOTAD has a linear objective function and linear constraints. Therefore, the model can be solved by any linear programming algorithm. Second, the Target-MOTAD formulation can be useful because agricultural decision-makers often wish to maximise the expected return, but are also concerned about net returns falling below a critical target. Due to this fact some researchers classify this risk programming model as part of the safety-first risk programming model [12].

\section{A risk programming model to optimise farm activities}

A mixed integer linear programming model is developed in this study, which determines the optimal crop sequences and livestock numbers for a given farm. The two competing criteria of profit maximisation and risk minimisation (risk resulting from weather unpredictability) for finding sequences of crops are explored. Cropping income risk will be considered as a constraint. In both criteria the model will be expected to determine an optimal croplivestock production strategy under the given assumptions. The farm management is seeking to maximise profits through efficient resource allocation.

\subsection{Assumptions}

Incorporating risk in farm planning is complex. It requires a clear identification of the various factors which have a substantial influence in the decision-making process of the farm. Crop production occurs subject to a complex mix of biological, agronomical and market factors. The representation of such a comprehensive system by means of a mathematical model certainly poses a challenge. Hence, it is essential to include the assumptions listed below in the process of developing a mathematical model.

1. With reference to the weather conditions under which the decision-maker is operating, the year-to-year variability of weather conditions on the farm is categorised into three discrete states of nature. The three states considered are: a normal year, a dry year and a wet year. In this study these three states of nature are used as the strategies of nature and the farm operates in three such possible states of weather conditions. The risk of planting crops resulting from unpredictability of weather 
changes is reflected on the variability of yields of crops in the three states of nature. The risk due to this yield variability of crops is shown by the differences in the income variation of the same cropping strategy at the three different states from the expected value. That is to say, the risk of cropping generated from weather variability is modelled as a deviation from the average of the three states of nature.

2. The profit, in real terms, remains constant over the period for which the problem is solved. This implies that the cost coefficients in the mathematical model remain constant.

3. The profit from a crop is dependent on the crop itself as well as the crop that was planted on the same soil during the previous year. Furthermore, the crop grown in the current year is dependent on the crop that was planted on the same soil two years ago. However, a crop that grew on the same soil three years ago has no effect on the current crop [35]. The influence of crops that grew a year ago or two years ago is reflected in the current crop by the cost coefficients.

4. The most important objective of this study is to develop an optimal sequence of crops that should be grown on the farm. In developing this sequence, it is assumed that the optimal sequence of crops forms a cycle $[6,7]$. Only cycles of one, two, and three years will be considered. The following assertions may justify the above assumption [6]:

- The computational effort to solve the mathematical problem rapidly increases as the number of years increases. Therefore, it is imperative to limit the number of years to a reasonable number that can be handled.

- From the practical perspective of the farmers and the dynamics of the markets, one may argue that the prices of the relevant crops do not remain constant for a long period of time. With this in mind, it is impractical to consider a long cycle, as it is impossible to predict future prices with certainty. Moreover, the longer the cycle, the higher the chance that price fluctuations will occur, so that the current cycle will no longer be optimal.

5. Area of arable land $(A)$ is divided into $T$ unit fields ( $T$ plots). The estimated yield of each crop in each field for the specified state of nature is known.

6. The farm is self-sufficient in forage and straw production; that is, production of forage and straw of the farm must satisfy the animals' consumption requirements for the given planning period.

7. The animals receive the required amount of feed and roughage that satisfies the ingredient and nutrient restrictions set by the decision-maker.

8. Animal sell/buy transactions are made at the start of the planning period. For that reason animals bought are considered in the animal feed intake planning and animals sold are excluded from the animal feed considerations. Moreover, no activity related profit is generated from those animals sold, as they are outside the activity in the planning period. The only return from these animals is, of course, the return from the sale of these animals. 
9. Animal types are categorised into three sets, namely, adult dairy cattle, young cattle and sheep. The number of young cattle is always $80 \%$ of the adult cattle. The reason for this is that each of the cows must calf at least once a year of which some is raised to produce milk when full-grown. Moreover, the only source of revenue from the animal production is revenue from sheep and the milk of adult cattle.

10. The loss from animal deaths and other natural hazards is negligible. Consequently, the cost incurred from such circumstances will not be accounted for in the mathematical model.

11. All crops produced are sold or used as animal feed during feed mix preparation in the period of study. This implies that no cost is incurred other than the production cost.

12. Since the variability of input prices is negligible, the risk resulting from this will not be investigated. Generally, the cost of different input components of the farm activity for cultivating a particular crop or managing an animal is considered as one grand cost component for each particular activity.

\subsection{Constraints}

The constraints considered in the model are briefly discussed in the following subsections.

\subsubsection{Land constraint}

Land is the vital factor in an integrated crop-livestock production system. The amount of crop available for the market, animal consumption and the amount of forage production is directly related to the amount of available land on the farm. Cropping strategies is defined and used as by Visagie (1997, 2004) and De Kock and Visagie (1998). Cropping strategies may be divided into one year, two year and three year strategies. A one year strategy means that the same crop is planted on the same land every year. A two year strategy means that the actual land on which this strategy is applied is divided into two equal parts. The crop planted on the first part in year 1 will be planted on the second part in year 2. In the same way the crop planted on the second part in year 1 will be planted on the first part in year 2. A three year strategy means that the actual land on which this strategy is applied is divided into three equal parts. The crop planted on part 1 in year 1 will be planted on part 2 in year 2 and on part 3 in year 3 . The crop planted on part 2 in year 1 will be planted on part 3 in year 2 and on part 1 in year 3 . The crop planted on part 3 in year 1 will be planted on part 1 in year 2 and on part 2 in year 3 . The land constraint limits the total available area of land allocated to the different cropping strategies. The constraint is given by

$$
\sum_{i=1}^{N} X_{i} \leq A
$$

where $A$ is the maximum area of land available (in hectares) and $X_{i}$ the area of land that is used to cultivate strategy $i$. 


\subsubsection{Limiting the number and size of strategies}

The integrated crop-livestock farmer has a choice of $n$ crops that may be grown on the given piece of land. Furthermore, the farm has $N$ possible crop rotation strategies from which a combination of strategies is to be implemented. It is, however, impractical in some cases to implement all the relevant feasible strategies on the farmland. It would, for example, be impractical when a huge number of strategies are scattered onto different little pieces of land. To accomplish this goal, we set an upper $(A)$ as well as an lower limit $(g)$ on the size of a strategy. The total number of strategies used is limited to $T$. This can be accomplished by incorporating the following constraints [36, 37]:

$$
\begin{aligned}
X_{i} & \leq \delta_{i} A \quad \forall i \\
X_{i} & \geq \delta_{i} g \quad \forall i \\
\sum_{i=1}^{N} \delta_{i} & \leq T \\
T & \geq 1 \\
X_{i} & \geq 0 \\
\delta_{i} & =\left\{\begin{array}{lll}
0 & \text { if } \quad X_{i}=0 \\
1 & \text { if } \quad X_{i}>0 .
\end{array}\right.
\end{aligned}
$$

\subsubsection{Income variability as a source of farm risk}

To assess the impact of a decision, an objective measure of the risk associated with the decision is required. This measure should evaluate the impact of the unpredictability of the states of nature. Consideration of risk is a key factor in selecting an optimal farm plan, as the introduction of risk into a production process affects the pattern of resource allocation and the level of production [9]. Assume that the future income variability which results from variations in weather in the adoption of the different cropping strategies is closely related to variability in the past. The crop income risk may then be estimated by income variability over some past time period $[14,12]$.

The approach followed here of introducing risk into the farm planning problem is an adaptation of Hazell's (1971) risk linear programming model. In adopting the constraints of this model, it is recognised that agricultural production activities take place in a risky environment. Moreover, it is true that a farm does not have a known income level because of the uncertainties in the weather states of each production period. The variance estimator is based on the sample mean absolute deviation instead of the more widely used sum of squares error (variance). This is a key point in the formulation, as it allows the incorporation of risk into a linear programming model. As discussed in $\S 2$, the objective function of the risk linear programming model formulated is the minimisation of the total absolute deviations. That is, the objective was minimising the risk level of an optimal farm plan. However, minimising risk is insufficient by itself and would result in plans with low income levels.

In this paper risk is introduced as a constraint (target level of risk) so that the model selects a combination of strategies that achieves a specified target level of risk with highest income. The mathematical formulation of incorporating risk as a constraint in the mathematical 
model follows below. The average income across the states of nature for strategy $i$ is calculated as

$$
C_{i}=\frac{1}{h} \sum_{\tau=1}^{h} C_{i \tau}
$$

where $C_{i \tau}$ is the income from strategy $i$ when state of nature $\tau$ prevailed (rand/hectare/ year). Equation (2) is the sample mean of net revenue per unit of the $i^{\text {th }}$ strategy across the $h$ states of nature. Given an appropriate sample of activity net revenues for the $h$ states of nature, an unbiased estimate [14] of the population mean absolute deviations (MAD) of an income from the strategies is given by

$$
M=\frac{1}{h} \sum_{\tau=1}^{h}\left|\sum_{i=1}^{N}\left(C_{i \tau}-C_{i}\right) X_{i}\right| .
$$

The expected value of $\left|\left(C_{i \tau}-C_{i}\right)\right|$ is the loss function [25]. Let the sum of the deviations of the income of the strategies from the sample mean (calculated in (2)), with nature in state $\tau$, be denoted by $L_{\tau}^{+}$if it is positive and $L_{\tau}^{-}$if it is negative. The variance of farm income (i.e. the risk) may be estimated using the sample mean absolute deviation (MAD) drawn from time-series or cross-sectional data. The advantage of the MAD estimator is that it can be included in a standard linear programming model. Then the relationship

$$
L_{\tau}^{+}-L_{\tau}^{-}=\sum_{i=1}^{N}\left(C_{i \tau}-C_{i}\right) X_{i}
$$

is true for all $\tau$. The interesting property of the above deviations is that both are nonnegative and only one of them can be greater than zero in each state of nature. That is, the deviation cannot be both positive and negative at the same time. Each measures the size of absolute value of the deviation of income of each strategy in a given state of nature from its mean.

In order to incorporate the downside risk in the model, the following constraints are necessary to consider the mathematical model:

$$
\begin{aligned}
\sum_{i=1}^{N}\left(C_{i \tau}-C_{i}\right) X_{i}+L_{\tau}^{-} & \geq 0, \quad \tau=1,2, \ldots, h \\
\sum_{\tau=1}^{h} L_{\tau}^{-} & \leq \lambda,
\end{aligned}
$$

where $\lambda$ is a parameter and with $\lambda_{\min }=0$.

\subsubsection{Animal feed activities}

Blended feed (Feed mix) The animal feeding policy and the crop production strategy influence each other. The land used to produce feed for animal consumption could be utilised for crop production. The farmer has to use the raw material produced on the farm when formulating the feed mix. The remaining raw material may be supplemented by purchasing from the market. The problem is to design a minimum-cost feed mix 
that satisfies certain requirements set by the farmer. Each of the possible ingredients has a different price, and each contains different proportions of various nutrients that the cattle need (a minimum amount of) annually. The feed mix is prepared from a set of raw materials and consists of a set of nutrients satisfying different restrictions. The mathematical model for the least-cost feed mix satisfying the nutritional and raw material requirement is given by the following linear programming model $[16,5,26]$ :

subject to

$$
\text { Minimise } w=\left\{\sum_{m=1}^{y} d_{m} Y_{m}\right\}
$$

$$
\begin{aligned}
p_{r} \leq \frac{\sum_{m=1}^{y} a_{r m} Y_{m}}{\sum_{m=1}^{y} Y_{m}} & \leq P_{r} \quad r=1,2, \ldots, x \\
e_{m} \leq \frac{Y_{m}}{\sum_{m=1}^{y} Y_{m}} & \leq E_{m} \quad m=1,2, \ldots, y \\
\sum_{a=1}^{l} \pi_{a}\left(W_{a}+N_{a}-Z_{a}\right) & =\sum_{m=1}^{y} Y_{m} \\
Y_{m}, p_{r}, P_{r}, e_{m}, E_{m}, W_{a}, N_{a}, Z_{a}, \pi_{a} & \geq 0 \\
W_{a}, N_{a}, Z_{a} & \text { Integer. }
\end{aligned}
$$

Here $d_{m}$ is the cost of raw material $m ; Y_{m}$ is the amount of raw material $m$ available; $p_{r}$ and $P_{r}$ are respectively the lower and upper bounds on nutrient $r ; a_{r m}$ is the yield of nutrient $r$ from raw material $m ; e_{m}$ and $E_{m}$ are respectively the lower and upper bounds on raw material $m ; W_{a}$ is the initial number of animals (type $a$ ) on the farm; $N_{a}$ is the number of animals (type $a$ ) bought from the market; $Z_{a}$ is the number of animals (type $a$ ) sold to the market; and $\pi_{a}$ is the feed requirement for one animal (type $a$ ).

Roughage requirements Roughage is part of the animal feed. Since the roughage requirement of animals is supplied totally from the farm production, it is necessary that the amount of roughage produced on the farm should satisfy the pasture demand of young cattle and sheep. In order to incorporate this activity into the general mathematical model, the formulation of a roughage availability constraint is necessary. Hence it is required that

$$
\sum_{a}^{l} \mu_{a}\left(W_{a}+N_{a}-Z_{a}\right)=\sum_{i=1}^{N} K_{i} X_{i},
$$

where $\mu_{a}$ is the roughage requirement of an animal (type $a$ ) and $K_{i}$ is the yield of roughage from strategy $i$.

\subsubsection{Availability constraints}

The farm considered in this study is an integrated crop-livestock production farm. The farm is assumed able to produce all or any combination of the crops considered. The harvested crops may be used either in the feed mix or may be sold to the market. Both crop sale and preparation of the feed mix are assumed dependent on the availability of crop 
yield in the farm crop production strategies. Therefore, this activity is termed availability [36], and is modelled by means of the constraints

$$
\begin{aligned}
\sum_{i=1}^{N} \beta_{i s} X_{i}-U_{s}-Y_{m} & =0, \quad s=1,2, \ldots, n ; m=1,2, \ldots, y \\
\beta_{i s}, X_{i}, U_{s}, Y_{m} & \geq 0
\end{aligned}
$$

where $U_{s}$ is the amount of crop type $s$ sold; $\beta_{i s}$ is the yield from crop type $s$ used in strategy $i$. These constraints ensure that the farm yields enough from the crops that the animals may be fed. The rest of the yield is sold to the market.

\subsubsection{Renting constraints}

Some of the resources available to the farm are not fixed. During the planning period the capacity of the available resources of the farm cannot match the demands of some activities. If the resources available are insufficient, it is assumed that the shortfalls may be supplemented through hiring or renting activities of additional units of the required resource. In this study the combine harvester and baling machine capacity of the farm is assumed to be fixed. If the demand for the capacity of such machines is greater than the capacity, additional units are required in order to cope with the demand.

Assume that the farm's combine harvester capacity is only $H$ hectares per year. In a given year, if the amount of land cultivated with wheat, canola and lupines is greater than the capacity of the machine, an additional amount of combine harvester capacity is necessary. That is

$$
\begin{aligned}
\sum_{i=1}^{N} \sum_{s=1}^{n} \alpha_{i s} X_{i}-R_{1} & \leq H \\
\alpha_{i s}, R_{1}, H & \geq 0
\end{aligned}
$$

where $\alpha_{i s}$ is the fraction of land cultivated by crop $s$ with strategy $i$ and $R_{1}$ is the number of hectares that need the extra combine harvester capacity.

Another restricting resource on the farm is the baling machine capacity. Silage and medics are either used in the preparation of feed mix or may be sold to the market. Both require baling on the farm. If the amount of silage and medics that need baling is more than the capacity of the baling machine of the farm, extra machine capacity may be hired at additional cost. Assume the capacity of the baling machine is $B$ tons/year and let $R_{2}$ tons/year be the extra capacity required. Then

$$
\begin{aligned}
\sum_{\text {Sil.,Med. }} U_{s}+\sum_{\substack{\text { Sil.,Med. } \\
U_{S}, Y_{m}, R_{2}, B}} Y_{m}-R_{2} \leq 0
\end{aligned}
$$

where $U_{s}$ is the amount of crop (type $s$ ) sold to the market and $Y_{m}$ is the amount of crop (type $m$ ) used in the feed mix. 


\subsubsection{Animal feed storage constraint}

The storage capacity of the storage area that the farm has for some feed material types is limited. Let $K_{m}$ (tons) be the maximum possible storage capacity available for raw material (type $m$ ). Then

$$
Y_{m} \leq K_{m}, \quad m=1,2, \ldots, y \text {. }
$$

\subsubsection{Livestock buying and selling}

The number of livestock kept on the farm depends on various factors. Some of these include availability of space, profitability, availability of feed and pasture. The number of animals kept on the farm may be constrained between a maximum and a minimum number. Let $\theta_{a}$ be the minimum number of animals (type $a$ ) and let $\Theta_{a}$ be the maximum number of animals kept on the farm in the planning period. Then

$$
\begin{aligned}
\theta_{a} \leq W_{a}+N_{a}-Z_{a} & \leq \Theta_{a}, \quad a=1,2, \ldots, l \\
\theta_{a}, W_{a}, N_{a}, Z_{a}, \Theta_{a} & \geq 0 \text { and integer. }
\end{aligned}
$$

\subsection{Objective function}

The main objective of the farm is to maximise profit from both activities of the farm, namely crop and animal production. The farmer's problem is to select the optimum combination of crop production strategies and number of animals that satisfy the different resource availability, resource restriction and risk constraints. The objective will thus be to maximise the total income minus the expenses. That is

$$
\begin{aligned}
\text { Maximise } G= & \sum_{s=1}^{n} V_{s} U_{s}-\sum_{i=1}^{N} C_{i} X_{i}+\sum_{a=1}^{l} f_{a}\left[W_{a}+N_{a}-Z_{a}\right] \\
& +\sum_{a=1}^{l} q_{a} Z_{a}-\sum_{a=1}^{l} b_{a} N_{a}-\sum_{m=1}^{y} d_{m} Y_{m}-\sum_{w=1}^{R} h_{w} R_{w} .
\end{aligned}
$$

\subsection{The model}

The final model is summarised below.

$$
\begin{aligned}
\text { Maximise } G= & \sum_{s=1}^{n} V_{s} U_{s}-\sum_{i=1}^{N} C_{i} X_{i}+\sum_{a=1}^{l} f_{a}\left[W_{a}+N_{a}-Z_{a}\right] \\
& +\sum_{a=1}^{l} q_{a} Z_{a}-\sum_{a=1}^{l} b_{a} N_{a}-\sum_{m=1}^{y} d_{m} Y_{m}-\sum_{w=1}^{R} h_{w} R_{w}
\end{aligned}
$$

subject to

$$
\sum_{i=1}^{N} X_{i} \leq A
$$




$$
\begin{aligned}
& X_{i} \leq \delta_{i} A \quad \forall i \\
& X_{i} \geq \delta_{i} g \quad \forall i \\
& \sum_{i=1}^{N} \delta_{i} \leq T \\
& T \geq 1 \\
& X_{i} \geq 0 \\
& \delta_{i}=\left\{\begin{array}{lll}
0 & \text { if } & X_{i}=0 \\
1 & \text { if } & X_{i}>0
\end{array}\right. \\
& \sum_{i=1}^{N}\left(C_{i \tau}-C_{i}\right) X_{i}+L_{\tau}^{-} \geq 0 \quad \tau=1,2, \ldots, h \\
& \sum_{\tau=1}^{h} L_{\tau}^{-} \leq \lambda \\
& p_{r} \leq \frac{\sum_{m=1}^{y} a_{r m} Y_{m}}{\sum_{m=1}^{y} Y_{m}} \leq P_{r}, \quad r=1,2, \ldots, x \\
& e_{m} \leq \frac{Y_{m}}{\sum_{m=1}^{y} Y_{m}} \leq E_{m}, \quad m=1,2, \ldots, y \\
& \sum_{a=1}^{l} \pi_{a}\left(W_{a}+N_{a}-Z_{a}\right)=\sum_{m=1}^{y} Y_{m} \\
& \sum_{a}^{l} \mu_{a}\left(W_{a}+N_{a}-Z_{a}\right)=\sum_{i=1}^{N} K_{i} X_{i} \\
& \sum_{i=1}^{N} \beta_{i s} X_{i}-U_{s}-Y_{m}=0, \quad s=1,2, \ldots, n ; m=1,2, \ldots, y \\
& \sum_{i=1}^{N} \sum_{s=1}^{n} \alpha_{i s} X_{i}-R_{1} \leq H \\
& \sum_{\text {Sil.,Med. }} U_{s}+\sum_{\text {Sil.,Med. }} Y_{m}-R_{2} \leq B \\
& Y_{m} \leq K_{m}, \quad m=1,2, \ldots, y \\
& \theta_{a} \leq W_{a}+N_{a}-Z_{a} \leq \Theta_{a}, \quad a=1,2, \ldots, l .
\end{aligned}
$$

All the variables should be greater than or equal to zero. The following variables should be integer as well: $W_{a}, N_{a}, Z_{a}, \theta_{a}, W_{a}, N_{a}, Z_{a}, \Theta_{a}$.

\section{Case study}

A typical farm situation located in the Koeberg area of the Western Cape was selected for the case study of the mathematical programming model. The farm has 1800 hectares of arable land, which is suitable for crop production. The farm's activities include crop 
production, dairy production and wool sheep production. The farm can grow wheat, canola, lupines, silage (oats) and medics. Moreover, it is assumed that the farmer has 16 choices of feasible cropping strategies (alternatives). The feasible cropping alternatives include monocropping, two-year crop rotation and three-year crop rotation. The feasible cropping strategies are selected based on the idea that these crops are grown currently in the region where the farm is located $[11,34]$. The 16 different feasible cropping alternatives (strategies) are given in Table 1.

\begin{tabular}{|c|c|c|c|}
\hline 1-year strategies & 2-year strategies & & 3 -year strategies \\
\hline 1. Wheat & Wheat/Medics & 9. & Wheat/Wheat/Medics \\
\hline 2. Medics & Wheat/Canola & 10. & Wheat/Canola/Medics \\
\hline \multirow[t]{6}{*}{ Pastures } & Wheat/Silage & 11. & Wheat/Canola/Silage \\
\hline & Wheat/Lupines & 12. & Wheat/Medics/Medics \\
\hline & Medics/Canola & 13. & Wheat/Wheat/Lupines \\
\hline & & 14. & Wheat/Silage/Medics \\
\hline & & 15. & Wheat/Canola/fallow \\
\hline & & 16. & Wheat/Medics/Lupines \\
\hline
\end{tabular}

Table 1: Possible strategies for the farmer.

\subsection{Data}

Three sets of data are used in this study, namely data for crop production, data for animal production and data for resource-hiring activities. The crop production data include cost of production, yield and price of crops for different strategies. These data are given in Table 2. The market prices (R/ton) of the different crops are: wheat R1359, Canola R1500, Lupines R1050, Silage R750 and Medics R750. The data are taken from [34].

The second set of data dealing with the livestock production activities refers to the annual animal food consumption requirements, and nutrient and ingredient restrictions. The restrictions on the number of animals the farm can sustain, profit earned and cost incurred from each type of animal per annum are required to investigate the farm plan [27].

At present the farm has 450 adult cattle and 1500 sheep. The number of young cattle is assumed to be $80 \%$ of the number of adult cattle. The number of animals the farm keeps is subject to different criteria. The restricting criteria include availability of food, availability of space and profitability of the operation. On average, adult cattle need 10 tons of blended feed per year each. The blended feed should contain on average at least $16.5 \%$ protein, $68 \%$ energy and $15 \%$ fibre. The feed mix is prepared on the farm and may consist of the raw materials, as shown in Table $3^{1}$. The young cattle are fed with both blended feed and roughage from the farm. Young cattle each require 2 tons of blended feed and 2 tons of roughage per year. The different restrictions on nutrients and ingredients of the blended feed for the young cattle are the same as for the adult ones. Roughage is the only food consumed by the sheep consume. A single sheep needs 0.5 ton of roughage per year. Due to space and operational business restrictions, the number of animals kept on the farm is constrained.

\footnotetext{
${ }^{1}$ The costs given for the first six crops are the production cost of the crops respectively.
} 


\begin{tabular}{|c|c|c|c|c|c|c|c|c|c|}
\hline Strategy & Income & & Wheat & Canola & Lupines & Silage & Medics & Roughage & Straw \\
\hline $\mathrm{Wh}$ & 1835 & $\begin{array}{l}\text { W } \\
N \\
D\end{array}$ & $\begin{array}{l}2.75 \\
2.50 \\
2.00\end{array}$ & & & & & $\begin{array}{l}0.72 \\
0.60 \\
0.42\end{array}$ & 1.80 \\
\hline $\mathrm{Me}$ & 1100 & $\begin{array}{l}\mathrm{W} \\
\mathrm{N} \\
\mathrm{D}\end{array}$ & & & & & $\begin{array}{c}5.00 \\
4 \\
2\end{array}$ & $\begin{array}{l}0.72 \\
0.60 \\
0.42\end{array}$ & \\
\hline $\begin{array}{l}\text { Wh- } \\
\text { Me }\end{array}$ & 1250 & $\begin{array}{l}\mathrm{W} \\
\mathrm{N} \\
\mathrm{D}\end{array}$ & $\begin{array}{l}1.65 \\
1.50 \\
1.20\end{array}$ & & & & $\begin{array}{l}2.80 \\
2.00 \\
1.00\end{array}$ & $\begin{array}{l}0.36 \\
0.30 \\
0.21\end{array}$ & $\begin{array}{l}0.90 \\
0.75 \\
0.53\end{array}$ \\
\hline $\begin{array}{l}\text { Wh- } \\
\mathrm{Ca}\end{array}$ & 1660 & $\begin{array}{l}\mathrm{W} \\
\mathrm{N} \\
\mathrm{D}\end{array}$ & $\begin{array}{l}1.65 \\
1.50 \\
1.20\end{array}$ & $\begin{array}{l}0.83 \\
0.75 \\
0.53\end{array}$ & & & & $\begin{array}{l}0.96 \\
0.80 \\
0.56\end{array}$ & $\begin{array}{l}0.90 \\
0.75 \\
0.53\end{array}$ \\
\hline $\begin{array}{l}\text { Wh- } \\
\text { Si }\end{array}$ & 1340 & $\begin{array}{l}\mathrm{W} \\
\mathrm{N} \\
\mathrm{D}\end{array}$ & $\begin{array}{l}1.54 \\
1.50 \\
1.12\end{array}$ & & & $\begin{array}{l}2.48 \\
2.25 \\
2.25\end{array}$ & & $\begin{array}{l}0.48 \\
0.40 \\
0.28\end{array}$ & $\begin{array}{l}0.90 \\
0.75\end{array}$ \\
\hline $\begin{array}{l}\text { Wh- } \\
\text { Lu }\end{array}$ & 1250 & $\begin{array}{l}\text { W } \\
\mathrm{N} \\
\mathrm{D}\end{array}$ & $\begin{array}{l}1.65 \\
1.50 \\
1.20\end{array}$ & & $\begin{array}{l}0.50 \\
0.50 \\
0.35\end{array}$ & & & $\begin{array}{l}0.72 \\
0.60 \\
0.42\end{array}$ & $\begin{array}{l}0.90 \\
0.75 \\
0.53\end{array}$ \\
\hline $\begin{array}{l}\mathrm{Me}- \\
\mathrm{Ca}\end{array}$ & 1300 & $\begin{array}{l}\mathrm{W} \\
\mathrm{N} \\
\mathrm{D}\end{array}$ & & $\begin{array}{l}0.83 \\
0.75 \\
0.53\end{array}$ & & & $\begin{array}{l}2.80 \\
2.00 \\
1.00\end{array}$ & $\begin{array}{l}0.72 \\
0.60 \\
0.42\end{array}$ & \\
\hline $\begin{array}{l}\text { Wh- } \\
\text { Wh- } \\
\text { Me }\end{array}$ & 1400 & $\begin{array}{l}\text { W } \\
N \\
\mathrm{D}\end{array}$ & $\begin{array}{l}2.20 \\
2.00 \\
1.60\end{array}$ & & & & $\begin{array}{l}1.86 \\
1.33 \\
0.67\end{array}$ & $\begin{array}{l}0.72 \\
0.60 \\
0.42\end{array}$ & $\begin{array}{l}1.20 \\
1.00 \\
0.70\end{array}$ \\
\hline $\begin{array}{l}\text { Wh- } \\
\text { Ca- } \\
\text { Me }\end{array}$ & 1433 & $\begin{array}{l}\mathrm{W} \\
\mathrm{N} \\
\mathrm{D}\end{array}$ & $\begin{array}{l}1.43 \\
1.30 \\
1.04\end{array}$ & $\begin{array}{l}0.66 \\
0.60 \\
0.42\end{array}$ & & & $\begin{array}{l}1.86 \\
1.33 \\
0.67\end{array}$ & $\begin{array}{l}0.72 \\
0.60 \\
0.42\end{array}$ & $\begin{array}{l}0.48 \\
0.40 \\
0.28\end{array}$ \\
\hline $\begin{array}{l}\text { Wh- } \\
\text { Ca- } \\
\text { Si }\end{array}$ & 1500 & $\begin{array}{l}\text { W } \\
N \\
\mathrm{D}\end{array}$ & $\begin{array}{l}1.29 \\
1.17 \\
0.94\end{array}$ & $\begin{array}{l}0.66 \\
0.60 \\
0.42\end{array}$ & & $\begin{array}{l}1.65 \\
1.50 \\
1.05\end{array}$ & & $\begin{array}{l}0.72 \\
0.60 \\
0.42\end{array}$ & $\begin{array}{l}0.48 \\
0.75 \\
0.28\end{array}$ \\
\hline $\begin{array}{l}\text { Wh- } \\
\text { Me- } \\
\text { Me }\end{array}$ & 1100 & $\begin{array}{l}\text { W } \\
N \\
D\end{array}$ & $\begin{array}{l}1.54 \\
1.40 \\
1.12\end{array}$ & & & & $\begin{array}{l}3.74 \\
2.67 \\
1.34\end{array}$ & $\begin{array}{l}0.96 \\
0.80 \\
0.56\end{array}$ & $\begin{array}{l}0.48 \\
0.40 \\
0.28\end{array}$ \\
\hline $\begin{array}{l}\text { Wh- } \\
\text { Wh- } \\
\text { Lu }\end{array}$ & 1400 & $\begin{array}{l}\text { W } \\
N \\
D\end{array}$ & $\begin{array}{l}2.20 \\
2.00 \\
1.60\end{array}$ & & $\begin{array}{l}0.33 \\
0.33 \\
0.23\end{array}$ & & & $\begin{array}{l}0.96 \\
0.60 \\
0.42\end{array}$ & $\begin{array}{l}1.20 \\
1.00 \\
0.70\end{array}$ \\
\hline $\begin{array}{l}\text { Wh- } \\
\text { Si- } \\
\text { Me }\end{array}$ & 1260 & $\begin{array}{l}\mathrm{W} \\
\mathrm{N} \\
\mathrm{D}\end{array}$ & $\begin{array}{l}1.29 \\
1.17 \\
0.94\end{array}$ & & & $\begin{array}{l}1.65 \\
1.50 \\
1.05\end{array}$ & $\begin{array}{l}1.86 \\
1.33 \\
0.67\end{array}$ & $\begin{array}{l}0.72 \\
0.60 \\
0.42\end{array}$ & $\begin{array}{l}0.48 \\
0.40 \\
0.28\end{array}$ \\
\hline $\begin{array}{l}\text { Wh- } \\
\text { Ca- } \\
\text { Gr }\end{array}$ & 1300 & $\begin{array}{l}\text { W } \\
N \\
D\end{array}$ & $\begin{array}{l}1.29 \\
1.17 \\
0.94\end{array}$ & $\begin{array}{l}0.66 \\
0.60 \\
0.42\end{array}$ & & & & $\begin{array}{l}0.96 \\
0.80 \\
0.56\end{array}$ & $\begin{array}{l}0.48 \\
0.40 \\
0.28\end{array}$ \\
\hline $\begin{array}{l}\text { Wh- } \\
\mathrm{Me}- \\
\mathrm{Lu}\end{array}$ & 1200 & $\begin{array}{l}\text { W } \\
N \\
D\end{array}$ & $\begin{array}{l}1.32 \\
1.20 \\
0.96\end{array}$ & & $\begin{array}{l}0.33 \\
0.33 \\
0.23\end{array}$ & & $\begin{array}{l}1.86 \\
1.33 \\
0.67\end{array}$ & $\begin{array}{l}0.72 \\
0.60 \\
0.42\end{array}$ & $\begin{array}{l}0.48 \\
0.40 \\
0.28\end{array}$ \\
\hline Gr & 0 & $\begin{array}{l}\mathrm{W} \\
\mathrm{N} \\
\mathrm{D}\end{array}$ & & & & & & $\begin{array}{l}1.50 \\
1.00 \\
0.50\end{array}$ & \\
\hline
\end{tabular}

Table 2: Income (R/ton) and yield (ton/ha) of each strategy in a wet, normal and dry year. The following abbreviations are used in this table: Wet (W), Normal (N), Dry (D), Wheat (Wh), Canola (Ca), Lupines (Lu), Silage (Si), Medics (Me), Roughage (Ro) and Grass (Gr). 
The maximum possible number of adult cattle the farm can keep is 600 and the lowest possible number of adult cattle the farm keeps due to business operational restrictions is 300. The maximum and minimum numbers of sheep the farm keeps are 500 and 2000 respectively.

\begin{tabular}{lrrrr}
\hline Ingredient & Protein $\%$ & Energy $\%$ & Fibre $\%$ & Cost (R/ton) \\
\hline Wheat & 12 & 80 & 3 & 80 \\
Canola & 20 & 80 & 15 & 80 \\
Lupines & 36 & 82 & 15 & 80 \\
Silage (Oats) & 5 & 55 & 29 & 10 \\
Medics & 15 & 52 & 25 & 10 \\
Straw & 8 & 45 & 37 & 190 \\
Lusern & 15 & 52 & 25 & 850 \\
Cotton-seed oil cake & 38 & 75 & 13 & 1100 \\
Fish meal & 60 & 71 & 0.1 & 3500 \\
Maize & 8.5 & 82 & 3 & 800 \\
Canola oil cake & 32 & 70 & 12 & 1000 \\
Bran & 14 & 62 & 10 & 480 \\
Molasses & 4 & 60 & 0.3 & 680 \\
Cotton seed & 20 & 84 & 24 & 750 \\
\hline
\end{tabular}

Table 3: Ingredients and their nutrient content in the feed mix preparation.

It is assumed that on average the farm generates an income of R10 450 per year from single adult cattle in dairy production. Income per single sheep from wool sheep production is assumed to be R250 per year. Another activity in animal production is the selling and buying of animals. From a single cattle and sheep sold, the farm can generate an income of R600 and R50 (the income is the interest on capital) per year respectively. Furthermore, if the conditions on the farm business are favourable for buying, the farm has an option of buying adult cattle and young sheep at the cost of R900 and R75 (the cost is the interest on capital) per year respectively.

A combine harvester is required for harvesting wheat, canola and lupines. The capacity of the existing combine harvester is 1200 hectares per year. The extra capacity cost of this machine is R1000/hectare. Another machine with fixed capacity is the baling machine. Silage and medics are either sold to the market at the existing market price or can be used in the preparation of blended feed for animal consumption. In each case both crops require baling. Baling is carried out on the farm with the existing machine capacity. The baling capacity of the machine is 2000 tons/year. If the demand for baling is more than the existing machine capacity, the farm should employ hired additional capacity. The cost of additional capacity for the baling is R150/ton.

\subsection{Results}

The mixed integer programming model was solved using the optimisation software Whats' Best!@. This section identifies farm plans (especially crop production plans) which maximise profit for different levels of risk. As discussed previously, the negative deviation from the expected value of the net return of a cropping sequence is considered as a measure of risk. This measure of risk is parameterised over feasible ranges, which correspond to an 
arbitrary lower bound (below this value the optimal strategies does not change substantially) of R494 $257\left(\lambda_{\min }\right)$ to an upper bound (above this value the optimal strategies does not change substantially) of R2 $237706\left(\lambda_{\max }\right)$, which is the maximum negative deviation allowed. The upper bound corresponds to the maximisation problem and the lower bound on risk corresponds to the minimum risk that can be achieved. This minimum risk value can be achieved by considering minimisation of risk as the objective function of the model. In order to investigate the effect of risk in the farm planning problem, the mathematical model was solved for the risk levels R494 257, R600 000, R1 000 000, R1 400 000, R1 600000 , R1 800000 , R2 000000 , R2 200000 , and R2 237706 . The summary of the results for such risk levels is shown in Table 4.

\begin{tabular}{|c|c|c|c|c|c|c|c|c|c|}
\hline & \multicolumn{9}{|c|}{ Risk constraining levels of $\lambda($ Rand $\times 1000000)$} \\
\hline & 0.494 & 0.600 & 1.000 & 1.400 & 1.600 & 1.800 & 2.000 & 2.200 & 2.230 \\
\hline Wh-Si & 165 & 285 & & & 767 & 987 & 612 & 237 & 165 \\
\hline Wh-Me & 340 & & & & & & & & \\
\hline Wh-Wh-Me & & & & & 1033 & & & & \\
\hline Wh-Me-Me & & 297 & & & & 813 & 1188 & 1563 & 1635 \\
\hline Wh-Wh-Lu & & & 790 & 925 & & & & & \\
\hline Wh-Si-Me & & & 514 & 824 & & & & & \\
\hline Grass & 1295 & 1218 & 496 & 50 & & & & & \\
\hline Sheep & 1955 & 1999 & 1671 & 848 & 502 & 581 & 871 & 1225 & 1693 \\
\hline Ad. cattle & 300 & 349 & 300 & 447 & 403 & 450 & 450 & 430 & 301 \\
\hline Ob. function & 2.022 & 2.382 & 3.341 & 4.175 & 4.428 & 4.700 & 4.974 & 5.246 & 5.285 \\
\hline
\end{tabular}

Table 4: Solutions at different risk levels. The following abbreviations are used in this table: Wheat (Wh), Canola (Ca), Lupines (Lu), Silage (Si), Medics (Me), Roughage (Ro), Grass (Gr), Straw (St), Adult cattle (Ad. cattle) and Objective function (Ob. function). The values of $\lambda$ and the objective function are given in millions of rand $(\times 1000000)$.

The solution of the mathematical model for the minimum-risk situation of a cropping plan is given in Figure 1. Under this minimum risk scenario, the solution suggests that $28 \%$ of the land should be allocated for the crop production. Due to the conservativeness of this decision scenario, $72 \%$ of the land is not allocated to any of the 15 cropping alternatives. The remaining land is used for roughage (grass) production, which is a low-risk alternative. The maximum profit that can be achieved in such a case is R2 022516 . The optimal model for this scenario specifies that the cattle production activity is carried out in the lowest minimum capacity possible, while sheep production is carried at the highest possible level.

At this risk level the production for crops (in tons) is as follows: wheat (produced and sold) 716, silage 346, medics 657 and straw 242 . The optimal feed mix contains 346 tons of silage, 242 tons of straw, 721 tons cotton seed oil cake, 864 tons maize, 74 tons braw, 207 tons molasses and 346 tons cotton seed. The model also indicates that 300 adult cattle and 1955 sheep should be kept.

If the risk level that the decision-maker incurs is allowed to increase from the minimum level to R1 000 000, the profit level of the farm increases by approximately $39.47 \%$. The 


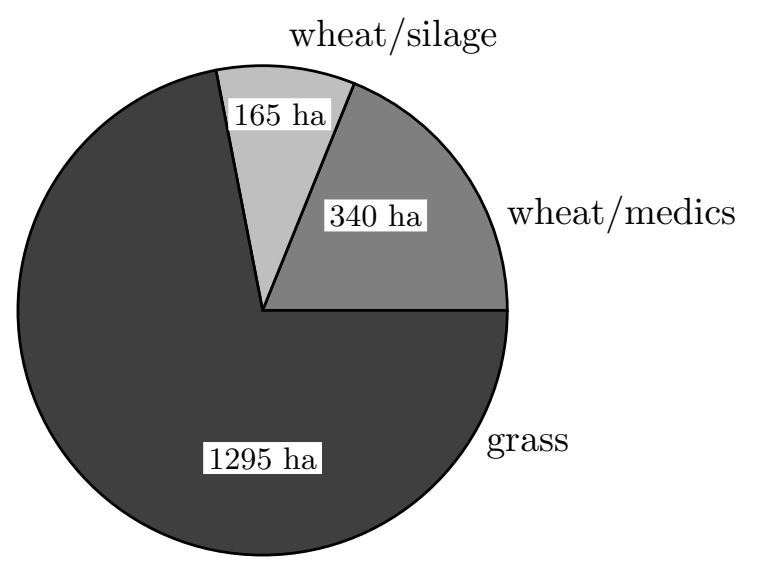

Figure 1: Farmland allocation for the minimum-risk situation.

solution from the mathematical model suggests that $72 \%$ of the land should be allocated for crop production. The land allocation solution of the model under this risk scenario is shown in Figure 2. The optimal solution for this risk level may summarised as follows: produce 2109.07 tons of wheat and sell it all; produce 234.73 tons of lupines and sell it all; produce 719.28 tons of silage and sell 373.28 tons of it; produce 660.54 tons of medics and sell 3.14 tons of it; keep 300 cattle and 1671 sheep. The optimal feed mix contains 346 tons of silage, 657.4 tons of medics, 242.2 tons of straw, 721.5 tons of cotton seed oil, 864.84 tons of maize, 74.4 tons of braw, 207 tons of molasses and 346 tons of cotton seed. The same analysis was also completed for different risk levels. The results are summarised in Table 4.

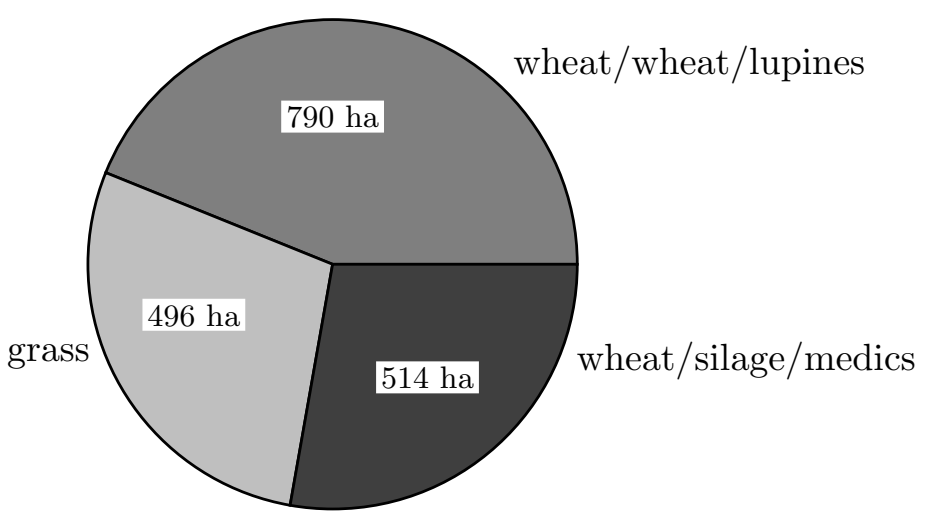

Figure 2: Farmland allocation with $\lambda=R 1000000$.

At the highest risk scenario the solution indicates that a combination of strategies including wheat-silage, wheat-medic-medic and wheat-medic are preferred. For the medium-risk levels wheat-silage-medics and wheat-wheat-lupines are selected. This roughly shows that increasing diversified cropping sequences are better for lower-risk scenarios. The cropping sequences wheat-wheat-medics, wheat-medics-medics and wheat-silage acreage increased as risk constraints were relaxed in the model. As expected, the value of the objective 
function increased as risk become less constraining. The choice of risk specification in the model results in significantly different crop mixes. Regardless of the degree of risk aversion, the optimal farm plan included a diversified cropping system. In all the optimisations performed, the solution suggests that forage crops should be planted. This can be attributed to the interdependence of the crop and livestock activities of the farm. Mono-crop systems (wheat and medics) failed to enter to the optimal solution in all the risk levels specified. Essentially, in the integrated crop-livestock environment diversification is the best option for profit maximisation and risk minimisation.

The question, however, remains which strategy would be optimal to follow for the planning period in question, as the differences in the alternatives offered by these different risk specifications are not minor. As there is no direct theory that guarantees an explicit choice from the different solution alternatives, the decision of which strategy to adopt will depend on the response of the decision-maker to risk. A risk-averse decision-maker will select strategies which will shield him to some extent from adverse situations. On the other hand, a decision-maker who is indifferent to risk levels will prefer strategies that give him the maximum profit possible.

A sensitivity analysis was performed on the risk parameter values. To analyse the model results for different values of risk aversion, the expected total sum of negative deviations, $\lambda$, was parameterised between the minimum value $\lambda_{\min }=\mathrm{R} 494257$ and $\lambda_{\max }=\mathrm{R} 2237706$. The model was solved for different risk values between these intervals. Figure 3 shows the model results reflecting the effect of increasing levels of risk aversion on the maximising profit objective function value.

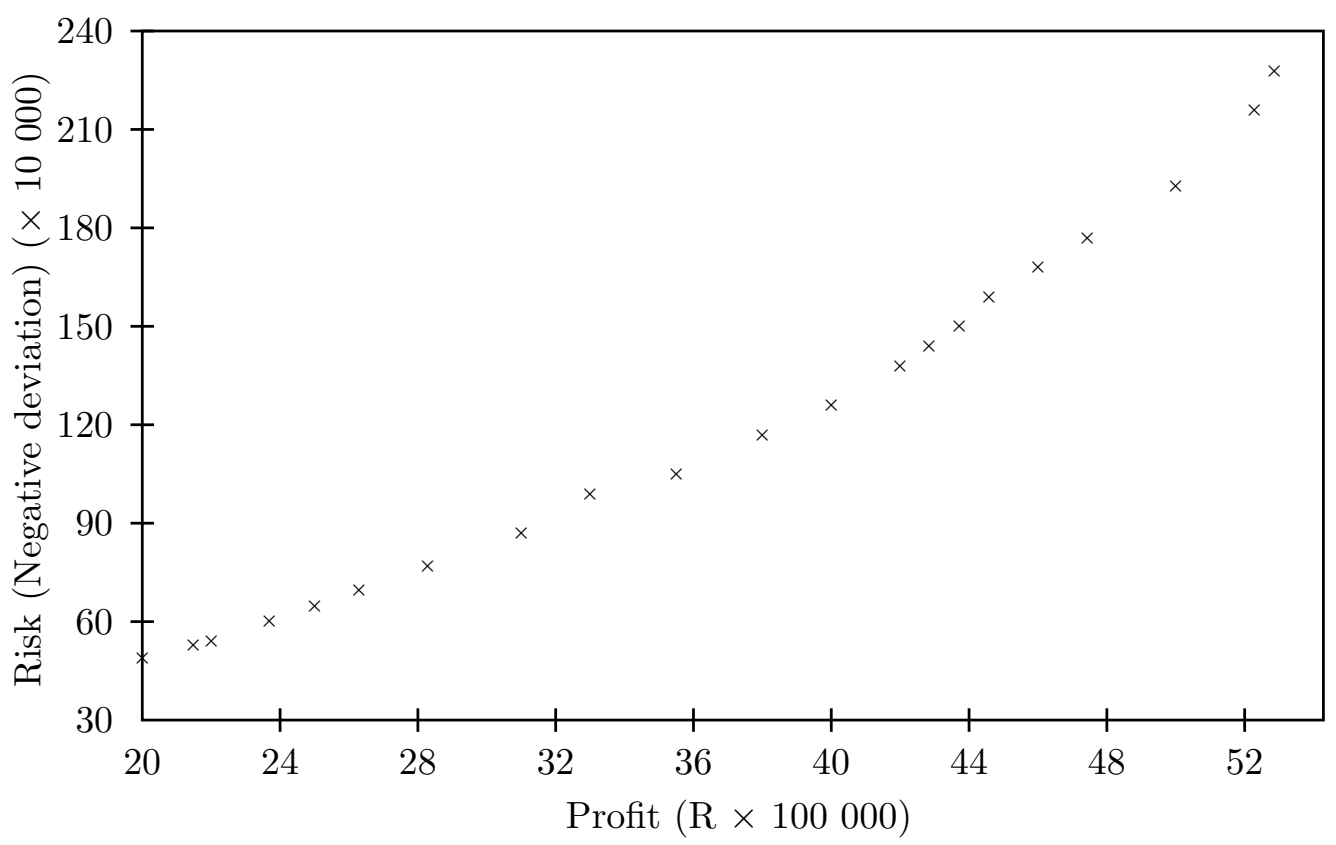

Figure 3: Profit risk frontier with increasing levels of risk aversion.

The analysis of the optimal farm plans for different levels of risk values showed that the profit level from the farm activities decreases when risk level increases. Results of the mathematical model suggest that profit can increase considerably with the decrease of 
risk-aversion level.

One evident property of the optimal solution profit-risk efficient set of the farm plan is that no one plan is superior to another with respect to both the performance measures, namely profit and risk. That is, farm plans with higher profit levels also have high measures of risk. It follows that production plans generating low profit also are associated with low risk levels. As highlighted above section, the selection of a farm plan depends on the decision-maker's objective preference.

Another property of the solution set suggests that the acreage utilisation for crop production depends on the amount of risk the decision-maker incurs. With a risk $(\lambda)$ of R500 000 between 25 and 30 percent of the farm is cultivated with rotary crop systems. This gradually increases up to a risk of about R1.5 million, from which point the whole farm is cultivated by some rotary crop system.

In general, based on the sensitivity analysis performed for different values of $\lambda$, the number of adult cattle the farm keeps increases with an increase of $\lambda$. This may be attributed to the favourable conditions created for animal production due to the availability of forage crops, which may replace the feed materials that can be bought from the market. For lower values of $\lambda$ (if the farmer is risk averse) the model solution favours the increase of sheep production.

\section{Conclusion}

The concept of crop yield risk as a measure of income variability was incorporated within the context of a farming model to allow the uncertainty (risk) constraints to interact with the specific set of crop production strategies. A mixed integer linear programming model was developed that addressed the following questions:

- What cropping strategies should be implemented and how much land should be allocated to the crop strategy selected?

- The feed mix required?

- What proportion of the crops should be sold to the market?

- What amount of extra resources should be hired?

- What number of animals should be kept and what are their feed requirement throughout the year?

The need to take risk into account in a farm planning problem allows the decision-maker to consider the trade-off between risk and profitability of the strategies selected for implementation. In the mathematical model developed this was achieved by building a model that captures the interdependencies between crop and animal production systems, the characterisation of typical years, that is, states of nature must be considered, as the prevailing state of nature directly affects the operation of both the crop and the livestock activities of 
the farm. The states of nature allow taking into account favourable and unfavourable conditions for the groups of crops considered. The negative deviation framework considered at the constraint level was used to transfer risk to the objective function that permitted the trade-off between risk and the profit margin analysed. For different risk profiles, the farming decision plan was investigated.

From a risk-averse farmer's point of view, conservative cropping strategies, wheat-silagemedic and wheat-canola-fallow, should be selected. If the state of nature is not favourable for farming activity, the model solutions suggest that the cattle production activity should be carried at its lowest limit possible. However, due to the availability of land for grass production (forage), the model indicates the intensification in the wool sheep production. One of the main cropping sequences selected as optimal strategy in all the above cases is the wheat-medic-medic cropping strategy. Planting medic after wheat may reduce the need for fertiliser because of the nitrogen-releasing properties of medics. As livestock is part of the enterprise mix of the farm under investigation, crop rotation, which is beneficial for the feed plan of the animals, is favoured by the model. As a result this rotation strategies are suitable for such a mix of enterprises.

\section{References}

[1] Anderson JR, Dillon JL \& Hardaker JB, 1977, Agricultural decision analysis, Iowa State University Press, Ames (IA).

[2] BArry CB, 1974, Portfolio analysis under uncertain means, variances and covariances, Journal of Finance, 29, pp. 515-522.

[3] BARRY PJ (ED.), 1984, Risk management in agriculture, Iowa State University Press, Ames (IA).

[4] Bigman D, 1996, Safety-first criteria and their measurement of risk, American Journal of Agricultural Economics, 78, pp. 225-235.

[5] De Kock HC \& Sinclair M, 1987, Multi-mix feedstock problems on microcomputers, Journal of the Operations Research Society, 38(4), pp. 585-590.

[6] De Kock HC \& Visagie SE, 1998, Wisselboustelsels in die Swartland, ORiON, 14(1), pp. 37-56.

[7] El-Nazer T \& MCCARL BA, 1986, The crop rotation: A modelling approach and a case study, American Journal of Agricultural Economics, 68, pp. 127-136.

[8] Freund RJ, 1956, The introduction of risk into a programming model, Econometrica, 24, pp. 253-263.

[9] Gabriel CS \& BAKer BC, 1980, Concepts of business and financial risk, American Journal of Agricultural Economics, 62, pp. 560-564.

[10] Hardaker JB, Huirne RBM \& Anderson JR, 1997, Coping with risk in agriculture, CAB International, Wallingford, Oxford. 
[11] HaRdy M, 1998, Towards sustainable crop production in the Swartland: A short review, Elsenburg Journal, 2, pp. 42-45.

[12] Hazell PBR \& Norton RD, 1986, Mathematical programming for economic analysis in agriculture, Macmillan Co., New York (NY).

[13] Hazell PBR, 1970, Game theory - An extension of its application to farm planning under uncertainty, American Journal of Agricultural Economics, 21, pp. 239-252.

[14] Hazell PBR, 1971, A linear alternative to quadratic and semivariance programming for farm planning under uncertainty, American Journal of Agricultural Economics, 53, pp. 53-63.

[15] Hazell PBR, 1982, Application of risk preference estimates in firm-household and agricultural sector models, American Journal of Agricultural Economics, 64, pp. 384390.

[16] Klein KK, Hironaka R, Heller CH \& Freese BS, 1986, Profit maximizing linear programming model for dairy cattle, Journal of Dairy Science, 69, pp. 10701080

[17] Kmiettowicz ZW \& Pearman AD, 1981, Decision theory and incomplete knowledge, Gower Publishing Company Ltd., Hampshire.

[18] Knight FH, 1921, Risk, uncertainty and profit, Harper and Row Publishers (Reprinted in 1965), New York (NY).

[19] Mapp HP, Hardy ML, Walker OL \& Persaud T, 1979, Analysis of risk management strategies for agricultural producers, American Journal of Agricultural Economics, 61, pp. 1071-1077.

[20] Markowitz HM, 1952, Portfolio selection, Journal of Finance, 7, pp. 77-91.

[21] Markowitz HM, 1959, Portfolio selection - efficient diversification of investments, John Wiley and Sons Inc., New York (NY).

[22] McCamley F \& Kliebenstein JB, 1987, Describing and identifying the complete set of target MOTAD solutions, American Journal of Agricultural Economics, 69, pp. 669-676.

[23] MCInnerney JP, 1967, Maxmin programming: an approach to farm planning under uncertainty, American Journal of Agricultural Economics, 18, pp. 279-289.

[24] MCInnerney JP, 1969, Linear programming and game theory models - some extensions, American Journal of Agricultural Economics, 20, pp. 269-278.

[25] Mood AM, Graybill FA \& Boes DC, 1974, Introduction to the theory of statistics, $3^{\text {rd }}$ Edition, McGraw-Hill International Editions, Statistics Series, New York (NY).

[26] Munford AG, 1989, A microcomputer system for formulating animal diets which may involve liquid raw materials, European Journal of Operations Research, 41, pp. 270-276. 
[27] Perry TW, 1982, Feed formulations, The Interstate Printers \& Publishers Inc, Danville (IL).

[28] Robinson LJ, Barry PJ, Kliebenstein JB \& Patrick GF, 1984, Risk attitudes: Concepts and measurement approaches. In BARRY PJ (ED.), Risk Management in Agriculture, Iowa State University Press, Ames (IA).

[29] Romero C \& Rehman T, 1989, Multiple criteria analysis for agricultural analysis, Elsevier Science Publishers, Amsterdam.

[30] Roumasset JA, 1974, Estimating the risk alternate techniques: Nitrogenous fertilization of rice in the Philippines, Review of Marketing and Agricultural Economics, 42(4), pp. 257-294.

[31] Tanaka DL, Krupinsky JM, Liebig MA, Merill SD, Ries RE, Hendrickson JR, Johnson HA \& Hanson JD, 2002, Dynamic cropping systems: An adaptable approach to crop productions in the Great Plains, Agronomy Journal, 94, pp. 957-961.

[32] Tauer LW, 1983, Target MOTAD, American Journal of Agricultural Economics, 65, pp. 606-610.

[33] VisagIE SE, 1997, Wisselboustelsels in kleingraangebiede, MSc Thesis, University of Stellenbosch, Stellenbosch.

[34] Visagie SE, 2004, Optimering van wisselboustelsels, Agrekon, 43(3), pp. 297-316.

[35] Wassermann VD, 1982, Wisselbou en Grondvrugbaarheid, Blad van Eendaagse Kleingraan-jaarsimposium, Kleingraanontwikkelingsvereniging, Stellenbosch.

[36] Williams H, 1999, Model building in mathematical programming, $4^{\text {th }}$ Edition, John Wiley \& Sons Ltd, New York (NY).

[37] Winston W, 1994, Operations research: Applications and algorithms, $3^{\text {rd }}$ Edition, Duxbury Press, Belmont (CA).

[38] Wolgin JM, 1975, Resource allocation and risk: A case study of smallholder agriculture in Kenya, American Journal of Agricultural Economics, 57, pp. 622-630.

[39] What'sBest, 2004, Lindo systems' index page, [Online], [Cited October 15th 2004], Available from http://www.lindo.com/

[40] Young DL, 1984, Risk concepts and measures for decision analysis, pp. 31-42 in BARRY PJ (ED.), Risk management in agriculture, Iowa State University Press, Ames (IA). 